\title{
ANARQUIA E FRAGMENTAÇÃO NAS RELAÇÕES INTERNACIONAIS: INTERAÇÕES ENTRE O DIREITO INTERNACIONAL E A ESCOLA INGLESA NO TOCANTE À LEGITIMA DEFESA PREVENTIVA
}

\author{
ANARCHY AND FRAGMENTATION IN INTERNATIONAL RELATIONS: \\ INTERACTIONS BETWEEN INTERNATIONAL LAW AND THE ENGLISH SCHOOL \\ REGARDING THE PREVENTIVE SELF-DEFENSE
}

Ricardo Soares Stersi dos Santos ${ }^{1}$

Ademar Pozzatti Junior ${ }^{2}$

\begin{abstract}
RESUMO - O presente artigo busca apresentar uma forma de interação entre a Teoria da Sociedade Internacional - a partir dos pensamentos de Martin Wight, Hedley Bull e Andrew Hurrel - e a Fragmentação do Direito Internacional, a partir do estudo da legítima defesa preventiva. Para tanto, serão consideradas as interpretações divergentes sobre o direito de legítima defesa preventiva como decorrência necessária das relações de cooperação e conflito entre os Estados, surgidas no seio de uma Sociedade Internacional Anárquica cujos sujeitos criam e aplicam as normas jurídicas que regulam suas relações. Por fim, apresentado o exemplo da interação entre Anarquia e Fragmentação aplicáveis à legítima defesa preventiva, será evidenciada a necessidade de um estudo interdisciplinar entre Direito Internacional e Relações Internacionais no campo do uso internacional da força, com a Teoria da Sociedade Internacional focada nos valores e normas comuns, cooperação e conflito, enquanto a Fragmentação procura constituir e, em parte, direcionar, as possibilidades de cooperação e conflitos percebidas pela Teoria da Sociedade Internacional.
\end{abstract}

PALAVRAS-CHAVE - Legítima defesa preventiva. Direito Internacional. Relações Internacionais. Interdisciplinaridade.

ABSTRACT - This article seeks to provide a possible interaction between the Theory of International Society or English School - from the thoughts of Martin Wight, Hedley Bull and Andrew Hurrel - and the Fragmentation of International Law, applied to the study of preventive self-defence. Therefore, it shall be considered the diverging interpretations of the right of preventive self-defence as a result of the relations of cooperation and conflict amongst States, arising in the context of an Anarchical International Society whose subjects create and apply the legal norms governing their relations. Finally, after presenting the example of the interaction between Anarchy and Fragmentation applicable to preventive self-defense, it shall be highlighted the need for an interdisciplinary study between International Law and International Relations in the field of international use of force, in which the Theory of International Society focus on values and common standards, cooperation and

\footnotetext{
${ }^{1}$ Mestre e Doutor em Direito pela UFSC. Professor do Programa de Pós-Graduação em Direito da UFSC. Professor do Programa de Pós-Graduação em Relações Internacionais da UFSC. PósDoutorado pela UFPE. E-mail: rstersi@hotmail.com.

${ }_{2}^{2}$ Mestre e Doutorando em Direito pelo PPGD/UFSC. Professor do Complexo de Ensino Superior de Santa Catarina (CESUSC). E-mail: juniorpozzatti@gmail.com
} 
conflict, whereas the fragmentation may constitute and, in part, directs, the possibilities of cooperation and conflict, as noted by the English School.

KEYWORDS - Preventive self-defence. International Law. International Relations. Interdisciplinarity.

\section{CONSIDERAÇÕES INICIAIS}

O princípio da não intervenção é a tradução jurídica de um valor comum da atual Sociedade Internacional, bem como a síntese de pelo menos três dos objetivos primários dessa Sociedade, quais sejam: preservação do sistema e Sociedade de Estados; manutenção da independência ou soberania externa dos Estados; manutenção da paz, sem a extinção da guerra.

É possível depreender que uma das consequências da tradução de tal valor seja, dentre outras, o incentivo aos membros da Sociedade em solucionarem pacificamente suas controvérsias: as diversas modalidades - auto ou heterocompositivas - bem como a expansão do âmbito de atuação dos diversos sistemas de solução de controvérsias - que abrangem desde controvérsias comerciais à proteção aos direitos humanos - atestam o cumprimento do princípio.

Porém, a consolidação do princípio da não intervenção como norma jurídica e valor comum da Sociedade Internacional não excluiu o meio último de solução de controvérsias internacionais, que é a guerra. É importante ressaltar que a completa supressão da guerra sequer é um dos objetivos da Sociedade Internacional.

Entre esses extremos, encontram-se o discurso cuja análise é proposta neste trabalho: a legítima defesa preventiva. Este discurso não justifica a deflagração da guerra sob qualquer pretexto, mas justifica ações violentas em casos - a princípio muito específicos, no qual a Sociedade Internacional ainda não produziu uma resposta satisfatória à prevenção ou no combate aos casos aos quais os Estados teriam permissão para agir. Esses discursos advogam medidas limitadas, tanto relacionadas ao uso da força militar, como nas possibilidades do seu emprego.

O referido discurso não busca romper com a não intervenção. Pelo contrário: tenciona apresentar a intervenção como implicitamente permitida em certas situações. Mais do que isso, podem ainda apresentá-la como valores comuns da 
Sociedade Internacional e, eventualmente, transformarem-se de demanda política ou moral para uma norma jurídica, uma exceção legal à norma geral.

Com suas especificidades e restrições operacionais, se afasta suficientemente para não ser considerado pacífica - vez que há o emprego da força -, porém não pode ser considerado como guerra no sentido tradicional do termo.

Nestas ações, aquele que pratica a legítima defesa é um Estado que se entende como agredido ou vítima em potencial, ou seja, talvez sequer tenha ocorrido alguma ação efetiva no sentido de invocar o direito à legítima defesa contido no artigo 51 da Carta da $\mathrm{ONU}^{3}$; o Estado que pratica a legítima defesa preventiva contra outro ator cuja suposta intenção de atacá-lo ainda não se materializou.

Verifica-se uma situação na qual os membros da sociedade, em especial os mais poderosos, sempre dentro do contexto de determinada controvérsia, tem buscado expandir as maneiras mediante as quais poderão solucioná-las. O alargamento das opções disponíveis ao membro poderoso coloca-o em posição de escolher qual o método mais eficaz não para composição satisfatória do conflito para ambos, mas para a consecução de seus próprios interesses ao mesmo tempo em que procura apresentar suas preferências como valores ou normas comuns de toda a sociedade internacional.

Para compreender a complexidade, com suas causas e consequências políticas e jurídicas, é necessário ultrapassar as barreiras teóricas que separam o estudo do Direito Internacional das Relações Internacionais. Assim, este artigo propõe a junção de duas teorias para auxiliar na compreensão de um fenômeno - a legítima defesa preventiva em específico -, que possui implicações nas arenas jurídica e política: a Escola Inglesa ou teoria da Sociedade Internacional e a Teoria da Fragmentação do Direito Internacional.

A Escola Inglesa, ou Teoria da Sociedade Internacional, não está baseada em uma projeto de realização de uma ordem moral abstrata e universal, tampouco numa

\footnotetext{
${ }^{3}$ Nothing in the present Charter shall impair the inherent right of individual or collective self-defence if an armed attack occurs against a Member of the United Nations, until the Security Council has taken measures necessary to maintain international peace and security. Measures taken by Members in the exercise of this right of self-defence shall be immediately reported to the Security Council and shall not in any way affect the authority and responsibility of the Security Council under the present Charter to take at any time such action as it deems necessary in order to maintain or restore international peace and security.
} 
luta incessante e amoral pelo poder. Entende que existe a Sociedade de Estados, que buscam satisfazer seus interesses dentro de um quadro comum de interesses, normas e valores.

Já a Teoria da Fragmentação do Direito Internacional procura explicar a expansão e aprofundamento simultâneos dos diversos ramos desse Direito, ou seja, ao mesmo tempo em que o Direito Internacional passa a regular um número cada vez maior de relações sociais internacionais, as normas destinadas à regulação dessas diversas condutas especializam-se de tal maneira que acabam por criar um novo regime jurídico.

Esse movimento simultâneo expansão/especialização tem como consequência principal a diferenciação funcional e normativa entre os regimes jurídicos decorrentes desse movimento, o que tende a gerar incongruências e incompatibilidades normativas dentro da própria estrutura do Direto Internacional.

Assim, na primeira parte deste trabalho, serão apresentados os aspectos mais relevantes de ambas as teorias para o tema proposto, bem como a incidência de ambas na análise do Direito Internacional como instrumento de manutenção ou modificação da Ordem Internacional.

Posteriormente serão apresentadas as modalidades de fragmentação do Direito Internacional mais relevantes ao presente estudo, quais sejam: o surgimento de norma especial divergente da geral e as diferentes interpretações dadas à mesma norma geral. Neste último item localiza-se a legítima defesa preventiva, que será analisada a partir das perspectivas da fragmentação e da Escola Inglesa.

Por fim, a partir da legítima defesa preventiva, será analisado como os diversos membros da Sociedade Internacional, mesmo com um quadro comum de interesses, normas e valores, discordam quanto à criação, aplicação ou interpretação de normas jurídicas, evidenciando as tentativas de ocultar a imposição de interesses particulares sob o manto do interesse geral e do Direito Internacional.

\section{INTERAÇÃO ENTRE A FRAGMENTAÇÃO DO DIREITO NTERNACIONAL E A ESCOLA INGLESA DAS RELAÇÕES INTERNACIONAIS}

\subsection{Escola Inglesa ou Teoria da Sociedade Internacional}


Primeiramente, é necessário estabelecer um quadro interpretativo quanto ao pano de fundo político no qual se desenvolve não apenas as condições para as expressões jurídicas das vontades políticas, como também uma sinopse do contexto político que possibilitaria ou limitaria a expansão normativa na regulação do uso da força.

Assim, parte-se do quadro traçado por Hedley Bull em "The anarchical society: a study of order in international politics": uma sociedade internacional descentralizada, cujos membros - os Estados - se relacionam de diversas maneiras, não apenas em competição incessante por poder. ${ }^{4}$ Dessas relações, valores comuns, regras e instituições são criados, modificados ou reforçados, que, por sua vez, atuam sobre os Estados, limitando ou direcionando suas ações.

Bull identifica a sociedade de Estados com a então Sociedade Internacional. A este respeito diz:

A sociedade de Estados (ou sociedade internacional) existe quando um grupo de Estados, conscientes de certos valores e interesses comuns, formam uma sociedade, no sentido de se considerarem ligados, no seu relacionamento, por um conjunto comum de regras, e participam de instituições comuns. Se os Estados hoje formam uma sociedade internacional, é porque, ao reconhecer certos interesses comuns e até certos valores comuns, eles se consideram limitados por certas regras nas suas relações recíprocas (BULL, 2002, 13. Tradução livre.) ${ }^{5}$

Ainda de acordo com o autor, a Sociedade Internacional possuiria três objetivos principais: a preservação do sistema de Estados e da Sociedade Internacional, a manutenção da soberania e da independência dos Estados e,

\footnotetext{
${ }^{4}$ Essa sociedade anárquica possui as características apontadas por Martin Wight, quais sejam: A Sociedade internacional é uma sociedade diferente de qualquer outra, pois é a forma de Sociedade mais inclusiva na face da Terra. Ela possui quatro peculiaridades:1 - É uma Sociedade única, composta das outras Sociedades mais organizadas que chamamos de Estados. Os Estados são seus membros principais e imediatos, mesmo que possa haver um sentido no qual seus membros fundamentais são homens. 2 - O número de seus membros é consequentemente sempre pequeno. Quase todas as Sociedades Nacionais contam seus membros em milhões; a Sociedade Internacional não comporta mais de duzentos. 3 - Os membros da Sociedade Internacional são mais heterogêneos do que indivíduos, e essa heterogeneidade é acentuada pelo seu pequeno número. Existe uma grande disparidade entre eles em tamanho territorial, posição e recursos geográficos, população, ideais culturais e organização social. 4 - Os membros da Sociedade Internacional são, em conjunto, imortais. Os estados de fato, vez por outra, morrem ou desaparecem, mas na maior parte dos casos eles ultrapassam de muito a duração da vida humana. São parcerias dos vivos com os mortos e com a posteridade. Suas políticas são baseadas na expectativa de sobrevivência, e eles consideram seu dever protegerem seus interesses vitais. Cf., WIGHT, 2002, p. 98-99

${ }^{5}$ A society of states (or international society) exists when a group of states, conscious of certain common interests and common values, form a society in the sense that they conceive themselves to be bound by a common set of rules in their relations with one another, and share in the working of common institutions.
} 
finalmente, da manutenção da $p^{6} z^{6}$. Para atingir esses fins, os Estados se valem de diversos mecanismos de cooperação, tais como o Direito Internacional, a diplomacia, as Organizações Internacionais e nos costumes e convenções de guerra. (BULL, 2002, 13-4)

Apesar da contribuição oferecida por Bull em "The anarchical society", devese levar em conta o período no qual foi escrito: o conflito entre as duas superpotências durante a Guerra Fria escondeu ou inibiu o surgimento de diversos aspectos políticos e econômicos sob o manto da rivalidade ideológica. A rivalidade ideológica também escondeu a variedade cultural e étnica de regiões historicamente instáveis, as quais, ao final e após a Guerra Fria explodiram em conflitos e guerras civis, alguns dos quais ensejaram intervenções humanitárias patrocinadas pela ONU ou mesmo unilaterais.

De modo a manter as propostas de Bull, porém sem deixar de lado os atuais desafios enfrentados pela Sociedade Internacional no campo da segurança coletiva, da tensão inerente entre o multilateralismo político-econômico e unilateralismo militar, faz-se necessário atualizá-las. Para tanto, o pensamento de Hurrel torna-se essencial nesse esforço de atualização.

Hurrel busca identificar e mapear a estrutura mutante da Sociedade Internacional pós-Guerra Fria e os dilemas daí surgidos, proporcionando um aprofundamento teórico das questões políticas de fundo norteadoras das ações humanitárias unilaterais.

Além de constatar as mudanças normativas e de práticas institucionais na criação, promoção e defesa dos direitos humanos, destaca a convivência entre a "antiga" agenda militar - prevenção de ameaças externas ao Estado, uso da força para reforçar a ação diplomática, manutenção de um equilíbrio de poder - e as "novas guerras" que supostamente têm surgido após a Guerra Fria.

Essas "novas guerras" envolveriam atores não estatais ou infraestatais. Suas causas estariam mais relacionadas ao colapso político e econômico, degradação

\footnotetext{
${ }^{6}$ A manutenção da paz descrita por Bull refere-se à ausência de guerra entre seus membros como condição de normalidade. A guerra, apesar de não ser proibida, seria apenas em ocasiões específicas e de acordo com os costumes e convenções estabelecidos. Ainda de acordo com Bull, a manutenção da paz estaria subordinada à preservação do sistema de Estados. Cf., BULL, 2002, p. 17-19
} 
ambiental e conflitos étnico-religiosos e as "novas guerras" estariam em sua maioria localizadas no Terceiro Mundo (HURREL, 2007, 174-6).

A convivência entre a agenda tradicional e as "novas guerras" leva a resultados diferentes, motivados por interesses divergentes ou conflitantes. Tais interesses podem gerar normas jurídicas igualmente divergentes ou mesmo operarem fora do sistema provido pelo direito internacional.

\subsection{O fenômeno da fragmentação do Direito Internacional}

Para tratar da fragmentação do Direito Internacional, partiu-se do relatório da International Law Commission (ILC) intitulado"Fragmentation of international law: difficulties arising from the diversification and expansion of international law"7 e do artigo "Fragmentation of International Law. Postmodern Anxieties?", ambos de autoria ou coautoria do diplomata e professor finlandês Martti Koskenniemi

O estudo encontra-se dividido em oito partes, duas das quais são de interesse direto para este artigo: os itens $B$ - "a fragmentação como fenômeno" - e $C$ "conflitos entre lei especial e lei geral".

O item $B$ traça os contornos da fragmentação ao identificá-la com a "emergência de regras e complexos normativos especializados e (relativamente) autônomos instituições legais e esferas de prática legal.", tendo como resultado "conflitos entre regras e sistemas normativos, práticas institucionais divergentes e, possivelmente, a perda de uma perspectiva global sobre o direito ${ }^{8}$ (ILC, 2006, §8).

Ainda no delineamento da fragmentação, a ILC aponta as duas principais características do fenômeno:

\footnotetext{
Por um lado, a fragmentação cria o perigo de regras, princípios, sistemas normativos e práticas institucionais conflitantes e incompatíveis. Por outro lado, reflete a rápida expansão da atividade jurídica internacional em diversos novos campos e na diversificação de seus objetivos e técnicas ${ }^{9}$ (ILC, 2006, §14. Tradução livre)
}

\footnotetext{
${ }^{7}$ Disponível em: http://untreaty.un.org/ilc/documentation/english/a_cn4_l682_add1.pdf Acesso em 05 novembro de 2011.

8 Emergence of specialized and (relatively), autonomous rules or rule-complexes, legal institutions and spheres of legal practice... The result is conflicts between rules or rule-systems, deviating institutional practices and, possibly, the loss of an overall perspective on the law.

${ }^{9}$ On the one hand, fragmentation does create the danger of conflicting and incompatible rules, principles, rule-systems and institutional practices. On the other hand, it reflects the rapid expansion of international legal activity into various new fields and the diversification of its objects and techniques.
} 
E, por fim, aponta os principais riscos:

A emergência de direitos novos e especializados, "regimes autossuficientes"
e sistemas de tradados limitados geográfica ou funcionalmente gera
problemas de coerência no âmbito do direito internacional. Novos ramos
especializados não surgem acidentalmente, mas buscam responder a novas
exigências técnicas e funcionais... Cada complexo normativo ou "regime"
vem acompanhado de seus próprios princípios, sua própria forma de
expertise e seu próprio "ethos", não necessariamente idêntico ao "ethos" da
especialização vizinha...Para o novo direito ser eficiente, ele
frequentemente inclui novos tipos de cláusulas ou práticas que podem não
ser compatíveis com o antigo direito internacional geral ou o direito de
algum outro ramo especializado. Frequentemente novas regras e regimes
são criados precisamente para desviar-se do que antes era regulado pelo
direito geral. Quando tais desvios se tornam generalizados e frequentes, a
unidade do direito sofre. ${ }^{10}$ (ILC, 2006, §15. Tradução livre)

No item C - "conflitos entre lei especial e lei geral" -, são apresentados três tipos de fragmentação: a oriunda de interpretações conflitantes da lei geral, a oriunda da emergência de uma lei especial à exceção da lei geral e a decorrente da diferenciação entre tipos de lei especial. Apesar da importância dos três tipos de fragmentação na compreensão do tema proposto, esta revisão somente considerará os dois primeiros tipos de fragmentação.

De acordo com o texto, o segundo tipo de fragmentação trata do surgimento de uma eventual norma como exceção à lei geral; esta nova norma necessitaria de exceções ou padrões de violação que, além de desviarem do prescrito pela lei geral, tais exceções ou padrões de violação se justificassem em razão das características especiais desse assunto.(ILC, 2006, §54, in fine ).

Além disso, essa eventual norma trataria melhor da questão, tanto por estar mais próxima do objeto que pretende regular, como também por ser mais precisa e de aplicação mais direta, se comparada à regra geral.

${ }^{10}[\ldots]$ emergence of new and special types of law, "self-contained regimes" and geographically or functionally limited treaty-systems creates problems of coherence in international law. New types of specialized law do not emerge accidentally but seek to respond to new technical and functional requirements... Each rule-complex or "regime" comes with its own principles, its own form of expertise and its own "ethos", not necessarily identical to the ethos of neighbouring specialization[ ...] In order for the new law to be efficient, it often includes new types of treaty clauses or practices that may not be compatible with old general law or the law of some other specialized branch. Very often new rules or regimes develop precisely in order to deviate from what was earlier provided by the general law. When such deviations become general and frequent, the unity of the law suffers. 


\subsection{O Direito Internacional como instrumento de manutenção ou de modificação da Ordem Internacional}

O presente item buscará estabelecer o papel do Direito Internacional como justificador de interesses diversos e como tal papel resulta na própria fragmentação ou seja, de que maneira os diferentes discursos e demandas contribuem para a expansão/aprofundamento normativo do Direito Internacional e, mais importante, de que maneira influenciam na manutenção ou modificação da Ordem Internacional.

O conceito de Ordem Internacional é adotado como sendo "um padrão de atividades que sustenta os objetivos elementares ou primários da sociedade de Estados, ou sociedade internacional."11 (BULL, 2002, p.9. Tradução livre.). Estes objetivos, já citados no item anterior, são complementados por Hurrel, pois, na visão deste autor, as mudanças ocorridas na Sociedade Internacional, após a publicação da "Anarchical Society", exigem reformulações e ampliações dos objetivos minimalistas trazidos por Bull.

Desta maneira, Hurrel (2007) apresenta três desafios que devem ser enfrentados pela Sociedade Internacional atual: a apreensão dos interesses compartilhados, o gerenciamento da desigualdade de poder e a mediação da diversidade cultural e conflitos de valores.

Uma Sociedade composta de sujeitos que criam e podem aplicar o Direito e que enfrenta complexos desafios para sua manutenção necessita de instrumentos capazes de apreender o interesse comum e para lidar, de alguma maneira, com as desigualdades de poder entre os Estados. Em outras palavras, é necessário um conjunto normativo, papel que pode ser assumido pelo Direito Internacional.

Assim, parte-se do pressuposto apresentado por Koskenniemi (2005), para quem o Direito Internacional seria uma via media que, apesar de receber influências decisivas da moral e da política, não se transforma em nenhum deles, mantendo sua autonomia e sua posição intermediária entre o conveniente e o justo.

Tal posição intermediária pode ser verificada no próprio surgimento do Direito Internacional: enquanto surge do consentimento ou comportamento estatal, o Direito

${ }^{11}[\ldots]$ pattern of activity that sustains the elementary or primary goals of the society of states, or international society 
Internacional é considerado "obrigatório, independente dos interesses ou opiniões do Estado contra o qual é invocado." ${ }^{12}$ Por outro lado, o Direito não pode ser completamente independente do comportamento, vontade ou interesse estatal, pois, caso o fosse:

[...] nós estaríamos perdidos no que diz respeito a onde encontrá-lo ou justificá-lo. Se o direito não possuísse nenhuma relação com o poder e a realidade política, ele seria um tipo de moralidade natural, um código normativo fechado o qual pré-existiria as opiniões e interesses dos Estados individuais. ${ }^{13}$ (KOSKENNIEMI, 2005, pp. 17-8. Tradução livre).

O que foi dito acima é dinâmico: ora se favorece o elemento concreto, ora a normatividade é privilegiada. Estes extremos necessitam de discursos que os expliquem e justifiquem e são classificados por Koskenniemi (2005) como padrões argumentativos ascendentes e descendentes.

$\mathrm{O}$ argumento descendente vê o Direito Internacional como normativamente objetivo, externo ao comportamento, interesse ou vontade estatal. Este padrão torna o direito eminentemente obrigatório e "a justificação não advém meramente do poder, mas 'ideias' normativas chamadas regras" ${ }^{\prime 4}$ (KOSKENNIEMI, 2005, p. 60. Tradução livre)

Por sua vez, o padrão ascendente procura a fundamentação do Direito Internacional justamente no comportamento, interesse e vontade dos Estados, buscando relacionar estes elementos com padrões de conduta adotados pelos mesmos, de modo a aproximar o direito da prática internacional (KOSKENNIEMI, 2005, pp. 59-63)

Os riscos corridos por ambas as posições são evidentes: no caso descendente, há o risco de tornar o Direito Internacional numa espécie de moralidade natural ou teoria objetiva da justiça, ao passo que o padrão ascendente poderia tomar o Direito Internacional como refém da prática, transformando-o em mais arma dentro arsenal disponível para a ação estatal.

\footnotetext{
${ }^{12}[\ldots]$ it is assumed to be binding regardless of the interests or opinions of the State against which it is invoked.

${ }^{13}$ On the other hand, law cannot be completely independent from behaviour, will or interest. If it were, we would be at a loss about where to find or how to justify it. If law had no relation to power and political fact, it would be a form of natural morality, a closed normative code which would pre-exist opinions or interests of individual States.

${ }^{14}$ Justification is not received from mere factual power but from normative 'ideas' called rules.
} 
Seria necessária, portanto, a aceitação de ambos os padrões como constituintes e direcionadores do Direito Internacional, tanto para entender as contradições e perigos inerentes à polarização como para mantê-lo distante e relativamente autônomo desses polos.

Assim, a constante dinâmica de oposição, associação e dissociação entre argumentos ascendentes e descendentes, entre concretude e normatividade, garantiriam ao Direito Internacional sua posição como discurso intermediário entre a política e a moral (KOSKENNIEMI, 2005, pp. 68-9).

Assim, como lembra a ILC (2006), "novos tipos de Direito especializados não emergem acidentalmente, porém buscam responder às novas exigências técnicas e funcionais" e afirmam que "[...] um direito que falhe em articular as experiências diferenciadas entre situações fáticas ou entre interesses e valores que parecem relevantes em certas áreas problemáticas seria, no geral, inaceitável, utópico e autoritário simultaneamente. ${ }^{15}$ (Tradução livre).

Os "novos tipos de direito especializados" ou diferentes interpretações de uma mesma norma são os instrumentos utilizados pelos sujeitos para avançar seus interesses. Considerando o papel estabilizador e universal do direito internacional, este seria um veículo mediante o qual, segundo Byers (1995), o exercício do poder puro é transformado em poder legítimo.

Dessa forma, no contexto da "realidade caleidoscópica na qual atores em competição lutam para criar sistemas normativos" ${ }^{16}$ que representem seus interesses particulares (KOSKENNIEMI, LEINO, 2002, p. 559. Tradução livre), "a questão jamais é se deve ou não utilizar o direito, mas sim qual direito ou direito de quem"17 e, por isso:

enquanto o direito internacional é falado, e dessa maneira aplicado, reflete a profunda constelação de poder iníqua atual, também oferece avenidas de resistência e experimentação. [O direito internacional] pode ser utilizado

\footnotetext{
${ }^{15} \mathrm{~A}$ law that would fail to articulate the experienced differences between fact-situations or between the interests or values that appear relevant in particular problem-areas would seem altogether unacceptable, utopian and authoritarian simultaneously.

${ }^{16}$ Kaleidoscopic reality in which competing actors struggled to create competing normative systems often expressly to escape from the strictures of diplomatic law.

${ }^{17}$ The question is never whether or not to go by law but by which law or whose law.
} 
para apoiar ou desafiar a hegemonia. (KOSKENNIEMI, 2005, p. XIV. Grifo do autor. Tradução livre.) ${ }^{18}$

Logo, é possível encontrar nessa linguagem os instrumentos necessários para elaboração de um discurso justificador para manter ou mudar a ordem internacional, com argumentos ascendentes ou descendentes.

\section{PROVÁVEIS MODALIDADES DE FRAGMENTAÇÃo APLICÁVEIS À EXPANSÃO NORMATIVA DO USO DA FORÇA}

\subsection{Surgimento de norma especial contrária à norma geral}

Essa modalidade é mais comum de fragmentação, por traduzir novas demandas em regimes específicos à exceção do regime geral anterior, ao invés de criar uma divergência interpretativa.

Para Koskenniemi e Leino (2002), a proliferação de regimes específicos a princípio não seria problemática, posta a descentralização normativa do Direito Internacional, tanto no âmbito da criação como na aplicação das normas: tal proliferação, portanto, seria inerente à natureza do próprio Direito.

Frequentemente, novas normas ou regimes jurídicos são desenvolvidos precisamente para desviarem-se do que era anteriormente provido ou não pela norma geral, o que se justifica pela natureza especial da demanda (ILC, 2006, §15).

Estas novas regras ou regimes jurídicos específicos são relativamente autônomos, ou seja, ainda permanecem vinculados às normas ou sistemas gerais anteriores não conflitantes, em especial às obrigações erga omnes e normas da categoria jus cogens.

Segundo a ILC (2006), este tipo de fragmentação necessitaria de exceções ou padrões de violação que, além de desviarem do prescrito pela lei geral, se justificariam em razão das características especiais desse assunto.

Porém, é importante ressaltar, como fazem Koskenniemi e Leino (2002), que o surgimento de normas ou regimes específicos contém o risco não de uma eventual incompatibilidade abstrata entre os sistemas específicos, mas sim a perda de

\footnotetext{
${ }^{18}$ While the way international law is spoken and thus applied reflects the profoundly inequitable constellation of power today, it also offers avenues of resistance and experimentation. It may be used to support or challenge hegemony.
} 
qualquer tipo de controle sobre os vários interesses particulares transformados em direito - de modo a dar ares de obrigatoriedade e universalidade ao particular. Desta maneira, as novas regras ou regimes jurídicos específicos podem ser vistos tanto como uma resposta às insuficiências ou falta de flexibilidade do sistema ou regra geral (PULKOWISKI; SIMMA, 2006, p. 529) ou como resultado de uma luta para imposição de interesses sobre os outros membros da Sociedade Internacional (KOSKENNIEMI; LEINO, 2002, p. 559).

É possível distinguir ao menos duas submodalidades de fragmentação que atuam na criação de normas específicas: aquelas que visam regulamentar de maneira mais aprofundada situações ou interesses especiais $e$ as que se apresentam como exceções à norma ou regime geral. A primeira visa complementar a regulação existente na norma geral, enquanto a segunda procura 0 afastamento da regra geral, porém sem negá-la.

As normas que visam regulamentar situações não percebidas ou suficientemente reguladas pela norma geral "tem evoluído como uma resposta às insuficiências ou falta de flexibilidade percebidas do sistema geral"19 (PULKOWSKI, SIMMA, 2006, p. 529. Tradução livre), ou, como já disse Vattel (2008), admite "[...] menos exceções que o geral; [pois] é ordenada com maior precisão e aparenta ter sido mais incisivamente pretendida".

Por sua vez, as normas específicas que se apresentam como exceções à regra geral são mais drásticas, na medida em que procuram afastar ao máximo a aplicabilidade das normas anteriores ou gerais da situação ou interesse que pretendem regular.

No caso dos eventuais padrões de violação que justificam a existência de uma nova regra "[...] a violação às vezes é em si de tal natureza que incorpora algum elemento de conformidade com a regra que está sendo violada. A distinção entre a violação de uma regra e conformidade com a mesma nem sempre é tão clara." ${ }^{20}$ (BULL, 2002, p. 132. Tradução livre)

${ }^{19}$ new special regimes of international law have evolved as a response to insufficiencies or the perceived lack of flexibility of the general system.

${ }_{20}$ the violation is sometimes in itself of such a nature as to embody some element of conformity to the rule that is being violated. The distinction between violation of a rule and conformity to it is not always a sharp one. 
Isto significa que, apesar de ocorrer uma violação ou padrões de violações, estas podem ser justificadas em razão do cumprimento da própria regra geral "violada"; a regra geral não tratou especificamente do objeto da violação, apenas tratou de regular determinado grupo de condutas de maneira mais detalhada. Consequentemente, o surgimento de norma específica divergente ou à exceção da norma geral oriundas de violações poderia significar a fragmentação em ação e não uma violação clara da normativa existente.

Outra questão fonte de controvérsia é o estabelecimento do que é norma especial e o que é norma geral. A relação que determina a posição de tais normas nem sempre é evidente e a aplicação de princípio geral do direito internacional e técnica interpretativa da lex specialis derrogat lex generali não é automática. Sua aplicação dependeria, dentre outros fatores, da possibilidade de frustração da aplicação da norma geral pela norma especial, das consequências a terceiros beneficiados pela norma geral e do grau hierárquico da norma geral (ILC, 2006, §§ 91-7).

\subsection{Diferentes interpretações da norma geral}

Esta modalidade de fragmentação atua no significado dado às normas, ou seja, na possibilidade de interpretações divergentes ou mesmo opostas de uma mesma norma ou conjunto normativo.

As interpretações diferentes sobre as mesmas normas diminuem a segurança e previsibilidade esperadas de uma norma jurídica.

Como notado pela ILC (2006), em caso de divergência, "os sujeitos de direito não são mais capazes de prever a reação das instituições aos seus comportamentos e planejar suas ações de acordo [com a reação agora incerta das instituições]". ${ }^{21}$

A questão de diferentes interpretações de uma mesma norma foi resumida por Aron:

\footnotetext{
${ }^{21}$ Legal subjects are no longer able to predict the reaction of official institutions to their behaviour and to plan their activity accordingly.
} 
As normas jurídicas precisam ser interpretadas. Seu significado nem sempre é evidente e sua aplicação em casos específicos gera controvérsias... Como os Estados possuem concepções jurídicas e políticas diferentes, 0 direito internacional do qual participam envolverá interpretações contraditórias... baseados nos mesmos textos, porém levando a resultados incompatíveis.22 (ARON, 2003, p. 109. Tradução livre)

Como ressaltam Leathley (2006), Koskenniemi e Leino (2002), Pulkowski e Simma (2006), Romano (1999) e outros, esta modalidade de fragmentação está intimamente relacionada - porém não restrita - à multiplicação de tribunais e outros órgãos judiciais internacionais, entre os quais não se verifica "a existência de nenhum grau de coordenação entre eles [os órgãos judiciais internacionais]". ${ }^{23}$ (ROMANO, 1999, p. 711)

Tais divergências interpretativas podem demonstrar tanto um eventual desejo de esvaziar ou modificar seu significado literal ou consensual como o desacordo em relação ao conteúdo ou aplicabilidade da norma ou conceito a um caso específico. Usualmente, porém, há um consenso que limita a eventual dissensão interpretativa da norma os valores e normas compartilhadas da Sociedade Internacional, impondo um pesado ônus probatório recairá sobre quem apresenta a nova interpretação.

Com isto em mente, será apresentado a seguir uma aplicação das divergências interpretativas sobre a legítima defesa preventiva.

\subsubsection{Diferentes interpretações sobre a legítima defesa preventiva}

Para ilustrar as principais consequências das interpretações divergentes sobre a mesma norma, será apresentado o exemplo das prováveis interpretações do art. 51 da Carta da ONU, contraposto ao suposto direito costumeiro de legítima defesa preventiva originado a partir do caso Caroline e a National Defense Strategy (NDS) do governo dos Estados Unidos.

O primeiro exemplo trazido diz respeito às implicações relacionadas ao direito "inerente" à legítima defesa e, de maneira menos controversa, à expressão "ataque

${ }^{22}$ Traduzido do inglês: Juridical norms need to be interpreted. Their meaning is not always evident and their application to specific case leads to controversy. Now international law does not determine an organ that, in regard to interpretation, holds the supreme power... As states have different juridical and political conceptions, the international law to which they subscribe will involve contradictory interpretations...based on the same texts but leading do incompatible results.

${ }^{23}$... without implying the existence of any degree of coordination among them. 
armado". O art. 51 dispõe: "Nada na presente Carta prejudicará o direito inerente de legítima defesa individual ou coletiva caso ocorra um ataque armado contra um Membro das Nações Unidas..." (Tradução livre.) ${ }^{24}$

A partir da leitura do art. 51, imediatamente surgem algumas perguntas: o que é abrangido pela expressão "direito inerente"? E o que deve ser considerado como ataque armado? As eventuais respostas - baseadas em "concepções jurídicas e políticas diferentes" - podem levar a resultados opostos, conforme será visto abaixo.

A primeira pergunta gira em torno da extensão da expressão "direito inerente", em especial sobre a existência um direito costumeiro de legítima defesa preventiva anterior à Carta. Aqui há duas correntes interpretativas principais acerca da abrangência da expressão "inerente": aqueles que negam o valor da expressão e os defensores da existência de um direito à legítima defesa preventiva pré-Carta.

A primeira corrente, de acordo com Byers (2005), baseia seu argumento nas normas sobre interpretação dos tratados, codificadas na Vienna Convention on the Law of Treaties (VCLT), em especial o art. 31 (1), que dispõe: "O Tratado será interpretado de boa-fé de acordo com o sentido comum dado aos termos do tratado no contexto e à luz de seu objeto e propósito." ${ }^{25}$ (Tradução livre)

Ao aplicar o disposto acima à interpretação do art. 51 da Carta, os opositores argumentam que "qualquer direito preventivo de legítima defesa preexistente de legítima defesa vem ser anulado pela exigência de 'ocorrer um ataque armado"' (BYERS, 2005, p. 97)

Já a segunda corrente defende a existência de um direito costumeiro à legítima defesa preventiva com base na permissividade contida na expressão "inerente".

Tal direito costumeiro teria sido formulado no século XIX e já teria os seus contornos delineados na troca de correspondências diplomáticas subsequentes ao incidente do vapor Caroline. (BROWNLIE, 2003, pp. 701-2)

\footnotetext{
${ }^{24}$ Nothing in the present Charter shall impair the inherent right of individual or collective self-defence if an armed attack occurs against a Member of the United Nations... A Carta das Nações Unidas (em inglês) encontra-se disponível no link: http://www.un.org/en/documents/charter/ . Acesso em 08 março de 2012.

${ }^{25}$ A treaty shall be interpreted in good faith in accordance with the ordinary meaning to be given to the terms of the treaty in their context and in the light of its object and purpose. $\mathrm{O}$ tratado completo encontra-se disponível no link: http://untreaty.un.org/cod/avl/ha/vclt/vclt.html . Acesso em 26 fevereiro de 2012.
} 
O referido caso pode ser resumido nos fatos que ocorreram em 1837, quando forças britânicas tomaram e incendiaram o vapor norte-americano Caroline, que estava ancorado em Fort Schlosser e se preparava para suprir uma rebelião no Alto Canadá com armas, suprimentos e voluntários dos Estados Unidos. Após o protesto norte-americano pela ação britânica e correspondência diplomática subsequente, foram elaborados pelo então Secretário de Estado Daniel Webster os critérios que deveriam ser satisfeitos pelos britânicos para justificar a uma ação de legítima defesa preventiva:

Sem dúvida, devemos reconhecer que, mesmo admitindo que efetivamente existem exceções resultantes da grande lei da legítima defesa, tais exceções devem limitar-se a casos em que a necessidade dessa legítima defesa seja urgente, incontornável, sem oferecer meios nem tempo para deliberação. (BYERS, 2005, p. 72. Grifo nosso)

Nesta linha, argumentam que a Carta não exclui a legítima defesa preventiva, pois a expressão "inerente" recepcionou este direito. Como não haveria conflito normativo, logo as duas normas existiriam simultaneamente.

Recentemente, alguns governos tem invocado o direito de legítima defesa preventiva, mesmo que potencial. O governo dos Estados Unidos, por exemplo, em sua National Defense Strategy (NDS), de 2002 invoca explicitamente o direito à legítima defesa preventiva ${ }^{26}$, citando inclusive os critérios delineados no caso Caroline.

Os EUA desde 2002 têm procurado "arrogar-se um direito de ação preventiva em legítima defesa que abarca situações remotas e incertas, particularmente decorrentes da dupla ameaça do terrorismo globalizado e das armas de destruição em massa". (BYERS, 2005, p. 19)

Por sua vez, a controvérsia acerca do que pode ser considerado ataque armado é de ordem qualitativa, ou seja, quais tipos de atos podem ser classificados como "ataque armado"?

Tal pergunta adquire relevância crescente à medida que os conflitos "tradicionais" - envolvendo declarações formais de guerra, manobras visíveis de forças armadas estatais através dos territórios dos beligerantes - têm sido em

\footnotetext{
${ }^{26}$ Apesar de a possibilidade do emprego preventivo da força em legítima defesa permear todo o documento, cf. especialmente pgs. 11-3 e 19-21. O documento completo encontra-se disponível no link: http://www.defense.gov/news/mar2005/d20050318nds1.pdf Acesso: 12 fevereiro de 2012.
} 
grande medida substituídos por outras modalidades de conflitos intraestatais, cujas raízes podem ser inúmeras: desde o colapso político ou econômico de um Estado até a presença de determinado territórios por grupos.terroristas.

Nestes casos, uma interpretação abrangente do que constitui legítima defesa, em especial em sua modalidade preventiva (caso seja aceita), poderá trazer ao menos duas questões relevantes para a sociedade internacional. Ora, caso uma interpretação mais favorável à legítima defesa preventiva se firme, qual(is) seria $(\mathrm{m})$ o(s) critério(s) para decidir se determinada ameaça é urgente, incontornável, sem oferecer meios nem tempo para deliberação? "Como se proteger de intervenções militares oportunistas justificadas por uma capa de legítima defesa"? (BYERS, 2005, 99)

As respostas para as questões acima, caso seja possível formulá-las na atual conjuntura, estão além das disposições da Carta da ONU, além dos critérios estabelecidos por Webster no caso Caroline. Todavia, uma resposta que ignore os aspectos jurídicos também será fatalmente incompleta, por negligenciar um conjunto normativo visto pela Sociedade Internacional como constituinte da Ordem Internacional.

\section{A FRAGMENTAÇÃO COMO RESULTADO DE PRESSÕES INSTITUCIONAIS DIVERGENTES}

Visto como o Direito Internacional pode ser usado para justificar interesses diversos, como isto resulta na fragmentação e, finalmente, as modalidades de fragmentação aplicáveis ao trabalho, este item tratará de apresentar as principais pressões institucionais relativas ao uso da força no contexto atual.

Apesar de o consenso da sociedade Internacional apontar para a direção da não intervenção, em situações específicas, determinados Estados valeram-se do uso da força na busca de seus interesses, contornando, alegando exceções à regra, seu cumprimento ou mesmo violando abertamente o consenso estabelecido após a entrada em vigor da Carta da ONU.

Tais atitudes seriam previsíveis numa sociedade que garante a seus membros a qualidade de juiz e executor daquilo que consideram seu direito, pois: 
[...] em um mundo constituído por potências soberanas e independentes, a guerra é o único meio pelo qual cada uma delas pode, em última instância, defender seus interesses vitais. Isto é igualmente verdadeiro caso uma potência considere que seus interesses requerem pacificação ou agressão (WIGHT, 2002, p. 95)

De fato, com a Guerra Fria, a força foi utilizada diversas vezes pelas duas superpotências e seus satélites na consecução de seus objetivos estratégicos.

Como lembra Hurrel (2007), 'mesmo durante a aclamada 'longa paz' [da Guerra Fria], houve 120 guerras nas quais mais de 25 milhões de pessoas foram mortas e 75 milhões ficaram feridas" ${ }^{27}$ (Tradução livre).

A Guerra do Vietnã, a invasão soviética ao Afeganistão e o apoio direto e indireto das superpotências, em especial da União Soviética aos movimentos de descolonização (bem como os conflitos deles decorrentes) e dos Estados Unidos aos golpes e ditaduras na América Latina e Caribe ilustram como o consenso podia ser facilmente ignorado.

Após a Guerra Fria, outras justificativas ganharam vigor, notadamente a intervenção militar por motivos humanitários e, após os atentados de 2001, a legítima defesa contra o terrorismo.

Em princípio, estas modalidades de uso da força violam o consenso baseado na não intervenção. Todavia, certas modalidades têm sido consideradas não como violações à norma geral da não intervenção contida na Carta da ONU, mas como exceções ou novas normas especiais que tratam de interesses não abrangidos pela norma geral.

Como foi mostrado anteriormente, os interesses nem sempre são convergentes e podem mudar de acordo com o tempo, resultando numa "realidade caleidoscópica na qual atores em competição lutam para criar sistemas normativos"28 que representem seus interesses particulares, escondendo sob a técnica legal uma "luta hegemônica, no qual cada um [dos atores em competição]

\footnotetext{
${ }^{27}[\ldots]$ even during the much acclaimed 'long peace' of the Cold War, there were around 120 wars in which over 25 million people were killed and 75 million were injured.

${ }^{28}$ [...] kaleidoscopic reality in which competing actors struggled to create competing normative systems.
} 
espera ver seus interesses específicos identificados com o interesse geral."29 (KOSKENNIEMI, LEINO, 2002, p. 561. Tradução nossa. Grifo dos autores.) ${ }^{30}$.

E concluem:

\begin{abstract}
Para entender o debate sobre a fragmentação como se tivesse a ver apenas com a coerência em abstrato é confundir-se sobre o que está realmente em jogo. Regimes especiais e novos órgãos fazem parte de uma tentativa de ir além da política atual que, de uma forma ou de outra, se mostrou insatisfatória. As tensões...expressam a preferência por parte de atores influentes no cenário internacional. Cada instituição fala sua própria língua profissional e procura traduzir isso para um esperanto global, e modo a ter seus interesses especiais aparecerem como naturais de todos.

${ }^{31}$ (KOSKENNIEMI; LEINO, 2002, 573. Tradução livre.)
\end{abstract}

No tocante ao uso da força, os atores em competição raramente se opõem ao consenso fundado na não intervenção. Ao invés disso, as pressões ocorrem no sentido de criar ou reforçar exceções à regra ou oferecer diferentes interpretações sobre o que pode ser considerado intervenção, para assim trazer determinados interesses para o discurso jurídico universal, como visto acima. Aspecto interessante nas lutas envolve quem defende a alteração ou manutenção normativa.

Em geral, os defensores das modalidades trazidas acima são os Estados localizados no Ocidente desenvolvido, muitos destes membros da Organização do Tratado do Atlântico Norte (OTAN).

Tais Estados defendem, com diferentes graus de vigor, interpretações expansivas ou novas regras a respeito da legítima defesa e/ou o direito ao uso da força por motivos humanitários. Mais do que apenas defender, esses Estados agem ou possuem o potencial para agir de acordo com as mudanças advogadas.

Do lado contrário, encontram-se diversos Estados africanos, asiáticos ou latino-americanos, muitos ciosos de sua independência recém-conquistada.

\footnotetext{
${ }^{29}[\ldots]$ hegemonic struggle in which each hopes to have its special interests identified with the general interest.

${ }^{30}$ Para uma crítica mais aprofundada sobre os perigos da aplicação prática da doutrina da harmonia de interesses, cf. CARR, Edward Hallet. Vinte anos de crise: 1919-1939. Uma Introdução ao Estudo das Relações Internacionais. Tradução de Luiz Alberto Figueiredo Machado. Brasília: Universidade de Brasília; São Paulo: Estado de São Paulo. 2001, 305 p.

${ }^{31}$ To read the debate about fragmentation as if it had to do only with coherence in the abstract is to be mistaken about what is actually at stake. Special regimes and new organs are parts of an attempt to advance beyond the political present that in one way or another has been revealed unsatisfactory. The jurisdictional tensions express deviating preferences held by influential players in the international arena. Each institution speaks its own professional language and seeks to translate that into a global Esperanto, to have its special interests appear as the natural interests of everybody.
} 
A maioria desses Estados foram colônias e/ou sofreram intervenções dos Estados ocidentais. Portanto, não surpreende que estes sejam os defensores mais ferrenhos da interpretação tradicional dos princípios da não intervenção e da soberania, considerando os argumentos contrários como meros sancionadores de intervenções por motivos escusos.

É interessante notar também não apenas as tentativas de fragmentação da normativa reguladora do uso da força, mas como a convivência de tais tentativas com a "antiga" agenda militar, voltada para a prevenção de ameaças externas ao Estado; o uso da força para reforçar a ação diplomática; a manutenção de um equilíbrio de poder - e as "novas guerras" que supostamente têm surgido após a Guerra Fria.

Essas "novas guerras" envolveriam atores não estatais ou infraestatais. Como já dito, suas causas estariam mais relacionadas ao colapso político e econômico, degradação ambiental e conflitos étnico-religiosos e as "novas guerras" estariam em sua maioria localizadas no Terceiro Mundo. (HURREL, 2007, 174-6).

A convivência entre a agenda tradicional e as "novas guerras" leva a resultados diferentes, motivados por interesses divergentes ou conflitantes. Tais interesses podem gerar normas jurídicas divergentes ou, ainda, operarem fora da ordem provida pelo direito internacional.

\section{CONSIDERAÇÕES FINAIS}

O presente estudo procurou inicialmente trazer os principais elementos de cada teoria para considerar a interação entre ambas no caso do direito internacional como instrumento de manutenção ou mudança da Ordem Internacional e como a oscilação entre tais extremos poderá levar à fragmentação do Direito Internacional.

Após, foram apresentadas as principais modalidades de fragmentação atinentes ao tema, focando no caso da legítima defesa preventiva como resultado de interpretações divergentes sobre a mesma norma, qual seja, o artigo 51 da Carta da ONU.

Por último considerou-se o papel dos valores e interesses divergentes na formação, aplicação e manutenção do Direito Internacional, oportunidade na qual 
buscou-se evidenciar o papel da assimetria de poder na sociedade internacional e como interesses divergentes podem gerar normas ou interpretações divergentes, sob o manto do interesse comum.

A complexidade e as especificidades de cada ocasião no qual a força foi ou poderá ser usada exigem a superação da análise meramente jurídica ou política.

Assim, procurou-se evidenciar ao longo deste artigo os pontos de interação entre as duas teorias, ilustrado no exemplo da legítima defesa preventiva como fruto de interpretações divergentes sobre uma norma e como resultado de pressões institucionais divergentes.

A fragmentação do Direito Internacional apresenta um entendimento sobre como o Direito se diversifica e expande, além de fazer alusões às diferentes vontades dos sujeitos que criam, interpretam e aplicam tais normas. Há referências eventuais sobre como as relações de poder e os interesses divergentes criam, modificam ou extinguem determinada norma ou conjunto normativo. Porém, no âmbito dos estudos sobre a fragmentação, há pouca menção sobre as causas que levam à fragmentação normativa. Apesar de importante, o estudo sobre como as normas se diversificam é uma contribuição insuficiente.

A Escola Inglesa, com seu foco nos valores e normas comuns, na cooperação e conflito, fornece um contexto mediante o qual torna possível integrar o estudo da fragmentação do Direito Internacional à realidade que este busca regular.

Ao estabelecer a relação entre as duas teorias, torna-se por demais evidente que fragmentação trata das consequências legais de uma Sociedade que, apesar de possuir um quadro de normas e valores, ainda discorda na aplicação ou mesmo no conteúdo de tais normas e valores. Característica esta inerente a uma Sociedade anárquica, composta de sujeitos que criam e podem aplicar normas que regulam suas relações.

Desta maneira a Escola Inglesa poderá servir como uma "âncora" teórica, que mantém os estudos sobre a fragmentação do Direito Internacional próximo da realidade que busca explicar, diminuindo assim os riscos de um estudo excessivamente abstrato e desvinculados dos outros elementos e instituições da Sociedade, ou de uma análise desatenta dos valores e normas cristalizadas no Direito Internacional. 


\section{REFERÊNCIAS}

BROWNLIE, lan. Principles of public international law. 6. ed. New York: Oxford University, 2003. $742 \mathrm{p}$.

BULL, Hedley. The anarchical society: a study of order in world politics. 3. ed. New York: Columbia University. 2003. 329 p

BYERS, Michael. A lei da guerra: direito internacional e conflito armado. Tradução de Clóvis Marques Rio de Janeiro: Record. 2007. 263 p.

Letting the exception prove the rule. Ethics \& International Affairs, New York, v. 17, n. 1, 01 abr. 2003. Disponível em: http://vlex.com/vid/letting-theexception-prove-rule-53214923 . Acesso em 01 ago. 2011

HURREL, Andrew. On global order: power, values and the constitution of international society. New York: Oxford University. 2007. 354 p.

KEEGAN, John. Uma história da guerra. Tradução de Pedro Maia Soares. São Paulo. Companhia das Letras 2006. 543 p.

INTERNATIONAL LAW COMMISSION. Fragmentation of international law: difficulties arising from the expansion and diversification of international law. Report of the study group of the International Law Commission finalized by Martti Koskenniemi. Genebra, 2006. 256 p. Disponível em: http://untreaty.un.org/ilc/documentation/english/a_cn4_1682_add1.pdf Acesso 05 nov. 11

KOSKENNIEMI, Martti. From apology to utopia: The structure of international legal argument. New York: Cambridge University, 2005. 683 p.

Fragmentation of international law: postmodern anxieties? Leiden Journal Of International Law, Leiden, n. 15, p.553-579, 2002.

The politics of international law. Oxford: Hart, 2011. $371 \mathrm{p}$.

LEATHLEY, Christian. An institutional hierarchy to combat the fragmentation of international law: has the ILC missed an opportunity? N.Y.U. Journal Of International Law, New York, n. 40, p.259-306, 2007-2008.

MARQUES, Eduardo Lorenzetti. Os limites jurídicos à atuação do Conselho de Segurança da ONU. Curitiba: Juruá, 2005. 258p.

PAULUS, Andreas L. Jus Cogens in a Time of Hegemony and Fragmentation: an attempt at a re-appraisal. Nordic Journal of International Law. Lund, 2005, v.74. pp.297-333. 
http://193.146.160.29/gtb/sod/usu/\$UBUG/repositorio/10270982_Paulus.pdf. Acesso 12 jan. 2012.

PULKOWSKI, Dirk; SIMMA, Bruno. Of planets and the universe: self-contained regimes in international law. European Journal Of International Law, Firenze, v. 17, n. 3, p.483-529, 2006.

WIGHT, Martin. A política do poder. Brasília, São Paulo: Universidade de Brasília, Instituto de Pesquisa de Relações Internacionais, São Paulo, 2002. 329 p

UNITED NATIONS. Charter of the United Nations. Disponível em: http://www.un.org/en/documents/charter/ . Acesso 12 jan. 2012.

Recebido para publicação: 07/12/2012

Aceito para publicação: 19/12/2012 